\title{
Action of probiotics on oral pathogens: Efficacy and controversies
}

\author{
Ricardo Gomes ${ }^{1}$, Maurício Miyazak ${ }^{1}$ and Idiberto Jose Zotarelli Filho ${ }^{2 *}$ \\ ${ }^{1}$ Faculty Leopoldo Mandic- Campinas, SP, Brazil \\ ${ }^{2}$ Post Graduate and Continuing Education (Unipos), São José do Rio Preto SP, Brazil
}

\begin{abstract}
Statistical data from studies on the effectiveness of probiotics do not follow a normal distribution, as the literary findings have decisive results correlate because of the difficulty of controlling the variables in each study. Probiotics have been used as flora modulator in response to oral health. The apparent results are considered from some microbiological factors (individual biofilm) that insert in individuals more or less susceptible groups to caries, periodontitis and halitosis. Nevertheless it is noteworthy that the use and the potential of probiotics are arguably directly proportional to other health conditions. Among these the socio-economic conditions stand out, those are rarely covered by research of this nature. This study aimed to track down several scientific studies that link positive and negative factors about the action of probiotics on pathogenic microorganisms such as Streptococcus mutans and Candida albicans. The methodology consisted of the advanced search in databases such as Pubmed, Scielo, Lilacs and various universities platforms, using the Mesh Terms: Probiotics, Streptococcus mutans, Candida albicans, Oral Pathology Microorganisms, Oral Health and Probiotics and Effects of Positive and Negative Oral probiotics. For the probiotic to be able to exert an anticariogenic effect; primarily the bacteria must be capable of adhering to the dental surface; second, it must become part of the biofilm; and finally, it must compete with cariogenic bacteria reducing the level of colonization of these. It was concluded that through pre-clinical and clinical action of probiotics on pathogenic microorganisms there is still enlightening results about the efficacy of probiotics, making it necessary to increase randomized multicenter studies.
\end{abstract}

\section{Introduction}

Statistical data from studies on the effectiveness of probiotics do not follow a normal distribution, as the literary findings have decisive results correlate because of the difficulty of controlling the variables in each study [1]. It is therefore imperative to include multicenter randomized studies on the efficacy of probiotics in control of oral diseases, since the incidence and prevalence of oral diseases such as caries and periodontal disease diseases reach significant percentages in developing countries and poor. For even better control the incidence of these diseases in developed countries [1,2].

Coconuts are standard anaerobic microorganisms Gram positive or negative. The Streptococcus species are gram-positive anaerobes Oral microbiota and Lactobacillus are (strictly Gram-positive) aerotolerant, but preferably grow in anaerobic atmosphere [2]. The Lactobacillus species differ from Streptococcus sp. particularly in morphological constitution $[2,3]$.

Probiotics have been used as flora modulator in response to oral health [4]. The apparent results are considered from some microbiological factors (individual biofilm) that insert in individuals more or less susceptible groups to caries, periodontitis and halitosis. Nevertheless it is noteworthy that the use and the potential of probiotics are arguably directly proportional to other health conditions among which stand out the socio-economic, which are rarely covered by research of this nature $[4,5]$.

Studies related to the action of bioregulators microorganisms contained in probiotic foods in the mouth are not experimental (in vitro or in SITM) and therefore not supporting [5]. One has to consider that other components contained in the formulation of these products, have various potential microenvironment interference and therefore favor or not the stability of the resident microbiota [6]. There is no doubt in the establishment of $S$. mutans as an important etiologic agent of dental caries and the expressive potential of cariogenic S. sobrinos. However, it should be considered that the action of Lactobacillus sp. in the progression of dental lesions, not even which does not consist of the etiology of dental caries [6,7].

Information contained in classic, basic and updated literature describing the Lactobacillus sp. are gram positive organisms baciliformes, facultative anaerobes, which eventually may have microaerophilia [7]. Another study reinforces the species Lactobacillus acidophilus are highly acidogenic with great efficiency both oxidative and fermentative $[7,8]$. Therefore, studies aimed at identifying and characterizing the different variants of Lactobacillus, especially $L$. case $i$ are of great relevance to the determination of various oral health conditions reported the effect of such probiotics $[8,9]$.

Many scientific efforts are aimed at demonstrating the feasibility of the use of strains of $L$. casei as a probiotic in dairy and other foods [10]. Lactobacilli in general, are proven of great importance for the food industry, however, taxonomic information related to the various

Correspondence to: Idiberto José Zotarelli Filho, Unipos - Post Graduate and Continuing Education, Street Ipiranga, 3460, São José do Rio Preto SP, 15020-040, Brazil, Tel: +55(17) 98166-6537; +55(17) 98803-7459; E-mail: m.zotarelli@gmail.com.

Key words: probiotics, Streptococcus mutans, Candida albicans, oral pathology, positive and negative effects of probiotics

Received: July 12, 2015; Accepted: August 17, 2015; Published: August 21, 2015 
groups of lactobacillus still remain inconclusive or enlightening [11]. However, it was found that Lactobacillus species are more significant in the progression of decay than the installation of this major dental disease. Other studies have reported that $L$. casei are more active and interfering the operation, and treatment of diseases, gastrointestinal diseases, particularly pediatric die $[11,12]$.

Thus, it can be considered very questionable data relevant to the purpose and benefit cost ratios with respect to probiotics and health of the oral cavity, since they have not been demonstrated correlations between various oral health conditions [12]. Many studies show only the effects of different probiotics in isolation and information regarding the $L$. casei of action are of little significance and without experimental description or control "in vitro" [12,13].

The opportunity to clarify many questions about probiotics and the various and possible therapeutic relationships and/or pathogenic including organic and natural flora, it is proposed in need character, experimental studies, supporting and descriptive of interspecific relationships and the probiotic microorganisms and the natural flora as well as chemical constraints of aggregated feed [14].

This study aimed to track down several scientific studies that link positive and negative factors about the action of probiotics on pathogenic microorganisms such as Streptococcus mutans and Candida albicans.

\section{Methodology}

The methodology consisted of the advanced search in databases such as Pubmed, Scielo, Lilacs and various universities platforms, using the Mesh Terms: probiotics, Streptococcus mutans, Candida albicans, oral pathology microorganisms, oral health and probiotics and effects of positive and negative oral probiotics.

\section{Development - Literature review}

\section{Probiotics}

According to the World Health Organization, probiotics are live microorganisms which when administered in adequate amounts confer health benefits to the host. As examples, the most studied species belong to the genus of Lactobacillus and Bifidobacterium which are commonly found in the oral cavity, including the carious lesions [1,2].

Generically, probiotics are products prepared with Lactobaccillus acidophilus, Streptococcus faecium, Bacillus subtilis and yeast in some cases [2]. The mechanism of action of probiotics is the competitive exclusion, competition for adhesion sites in the digestive tract, stimulation of immunity by most lactic acid production, decreased production of toxic amines, increased availability of amino acids to absorption sites, saving energy and increase the availability of vitamins and enzymes [2-4].

As an example of the main microorganisms used as probiotics, there are the bacteria belonging to the genus Bifidobacterium (B. bifidum, B. breve, B. lactis, B. longum and B. thermophilum) and Lactobacillus (L. acidophilus, L. delbrueckii, L. helveticus, L. casei, L. fermentum, L. reuteri, $L$. johnsonii, $L$. plantarum, $L$. rhamnosus and L. salivarius) and the bacteria Enterococcus faecium and Streptococcus thermophilus [2-5]. In addition, bacteria belonging to the Lactobacillus genus are considered sure. However, bacteria called Streptococcus, Enterococcus and Candida are opportunistic pathogens [5].

The beneficial action of the probiotic relates to the determination of best performance indexes reaching higher productivity, increase in weight gain and better feed conversion. Still occurs by reduction of intestinal colonization by some pathogens such as salmonella [6]. The mechanisms of action of probiotics relate to the production of compounds with antimicrobial activity, nutrients and competition for adhesion sites, changes in the microbial metabolism by increasing or decreasing enzyme activity and stimulating host immunity [7-10].

Thus, to appear beneficial effects, probiotic bacteria need to submit minimum number of Colony Forming Units. Furthermore, the criteria for selection of probiotic bacteria are the genre, stability compared to gastric acid and bile, ability to adhere to mucosal, ability to colonize at least temporarily the microenvironment of interest and ability to produce antimicrobial compounds [11-14]. Thus, the probiotics should adhere to dental tissue as part of biofilm and compete with the growth of cariogenic bacteria and periodontal pathogens [15].

In relation to immune stimulation, probiotics act on the immune response by interacting with the mesenteric lymph nodes, increasing immunoglobulin A $[1,16]$. In addition, other health benefits for the host are control and stabilization of intestinal microbiota, increased resistance to gastrointestinal colonization by pathogens, lactose digestion, relief from constipation and increased absorption and Minerals vitamin production [1,17-20].

Yet, as benefits of probiotics are listed decreased risk of colon cancer, decrease in cardiovascular disease and plasma concentrations of cholesterol, antihypertensive effect, reducing ulcerative activity of Helicobacter pylori, colitis control induced by rotavirus and Clostridium difficile, preventing urogenital infections and inhibition of mutagenicity $[2,3]$.

\section{Action of probiotics in Streptococcus mutans}

Published studies have shown the effects of probiotics on reducing the incidence of cavities, in which the reduction took Streptococcus mutans in the oral cavity mainly with the probiotic L. reuteri ATCC 55730 [1- 5]. From samples in the tooth surface and healthy oral mucosa were identified strains of $L$. salivarius BGHO1, $L$. fermentum BGHO36 and BGHO 64, L. gasseri and L. delbrueckii BGHO89 subsp lactis BGHO99 who had antagonistic action on Ataphylococcus aureus, Enterococcus faecalis, Micrococcus flavus, Salmonella enteritidis, Streptococcus pneumoniae and Streptococcus mutans, except on the growth of Candida albicans. Moreover, strains of L. gasseri and L. salivarius BGHO89 BGHO1 were tolerant to low $\mathrm{pH}$ and high concentration of bile salts.

Added to this, to evaluate the effect of the daily intake of a mixture of probiotics on the amount of Streptococcus mutans in the oral cavity, forty patients, aged 4 to 6 years, with a high risk of dental caries were studied. It was observed that both groups had similar microbial counts at baseline ( $>0.05)$ and there was significant reduction in the count at the end of the study $(\mathrm{p}<0.05), 15$ days after ingestion of the suspension [2].

In addition, another study showed the effect of probiotic consumption on yoghurt against cariogenesis in children. The randomized, double-blind study was conducted in 24 healthy children in the case and 25 children in the control group [10]. The yoghurt containing Bifidobacterium lactis $\left(1 \times 10^{6}\right.$ per gram $)$ was consumed once a day for children and healthy control group consumed ordinary yogurt. There was a statistically significant reduction in Streptococcus mutans $(\mathrm{p}=0.009)$. For the probiotic is able to exert a anticariogenic effect, primarily the bacteria must be capable of adhering to the dental 
surface; second, it must become part of the biofilm; And finally, it must compete with cariogenic bacteria reducing the level of colonization of these [11-16].

Contradictory works have also been published regarding the positive action of lactobacilli against $S$. mutans [17-23]. As a corollary, the efficient production of organic acids is a common feature of both Lactobacillus and Bifidobacterium may be detrimental to oral health. As an example, we evaluated the cariogenicity of probiotic bacteria Lactobacillus salivarius in rats and observed that these probiotic microorganisms promoted increased activity of cariogenic $S$. mutans [24-30].

These same microorganisms, however, have been related to oral health benefits, such as the production of inhibitory substances of Streptococcus sobrinus growth as well as reducing the risk of caries in children 3-4 years of age after milk intake containing Probiotic [31-34].

In addition, consumption of yogurt containing Lactobacillus reuteri decreased the Streptococcus mutans count [2,35]. Further, similar results were also obtained with strains of Bifidobacterium or Lactobacillus reuteri [36]. It is also demonstrated that there was no increase in the Streptococcus mutans count when administered with a mixture of Lactobacillus probiotics in the form of capsules or liquid [37].

Still, there was a literature review work showing the scarcity of studies that relate the action of probiotics and oral health [1-3]. Then work published between 2014 and 2015 also showed information gaps on the subject. Only found 14 studies with this approach, but all assessed the installation of probiotic bacteria or decrease/increase in pathogens after ingestion of products containing probiotics in saliva samples and is not found studies that evaluated the installation of these microorganisms in the biofilm.

In the installation of probiotic bacteria in the biofilm, it is necessary to ensure the survival of probiotic bacteria in the food product; the food must contain at least one population of $10^{7} \mathrm{UFC} / \mathrm{g}$ of viable probiotic bacteria [38]. However, it has been proposed by the FDA and the WHO minimum daily dose of probiotic culture is considered therapeutic and $10^{9}$ to $10^{8} \mathrm{CFU}$, which corresponds to a daily intake of $100 \mathrm{~g}$ of a product containing 106-107 CFU/g [2,39].

Further, probiotics may have action against microorganisms that are involved in periodontal disease $[1,2,40]$. Characterized lactobacilli isolated from the saliva and fluid subgingival of 67 healthy individuals. The results showed that most of the strains had the ability to inhibit the growth of periodontitis-related pathogens, Aggregatibacter actinomycetemcomitans, Porphyromonas gingivalis, intermediate as well as the etiological agent of dental caries, Streptococcus mutans. However, there are information gaps that the Lactobacillus were present due to the frequent consumption of dairy products, leading to temporary settlement, or if the oral environment was their permanent habitat.

Changes to the microflora in the oral cavity results in an overgrowth of bacteria including Streptococcus sorbinus, S. mutans and S. gingivalis are known to be the leading cause of tooth decay. Was isolated species of lactobacilli 10 subgingival salivary and healthy humans and conducted a study to evaluate the characteristics oral lactobacilli [40]. All strains were tested for antimicrobial activity against oral pathogens, low $\mathrm{pH}$ tolerance and bile content, and it was concluded that the strains of Lactobacillus plantarum, Lactobacillus paracasei, Lactobacillus salivarius and L. rhamnosus showed significant antimicrobial activity.
Another important example is the probiotic L. rhamnosus, more safe for teeth that lactic acid producing bacteria, it does not ferment sucrose. Additionally, L. rhamnosus inhibit Streptococcus mutans, however, the oral cavity colonization by L. rhamnosus little is known [1]. Added to this, we evaluated the effect of chewing gums over 3 weeks with probiotic over the salivary levels of Streptococcus and lactobacillus, and concluded that the chewing gum containing probiotic bacteria daily salivary reduces the Streptococcus mutans significantly [2].

\section{Action of Probiotics in Candida}

The main species of Candida in the oral cavity are C. albicans, C. glabrata, C. tropicalis, C. pseudotropicalis, C. guilliermondii, C. krusei, C. lusitaniae, C. parapsilosis, C. stellatoidea and C. dubliniensis, and that C. albicans is the most aggressive. In an attempt to increase preventive measures and treatment of candidiasis, bacterial microbiota plays an important probiotic role. However, it is still not well known mechanism of action of probiotics against candidiasis [2].

Thus, the literary findings show positive and negative results of the effect of probiotics on Candida. As an example, we analyzed the coexistence of Lactobacillus acidophilus and Candida healthy mouth and the results revealed that there is a balance between the two species, namely Candida nutritional stimulants serve as the Lactobacillus and these would control the excessive growth of C. albicans by producing lactic acid [3].

In a similar response, showed the relationship between C. albicans and L. casei, L. plantarum, L. fermenti, L. acidophilus and was also the result of balance and control of the C. albicans growth $[5,6]$. In preclinical studies, analyzed to Candida colonization in the oral cavity of mice with $L$. acidophilus probiotic bacteria have shown that Lafti L10 and C. albicans was reduced due to the stimulation of IL-4 and IFN- $Y$ and the concentration of NO [4].

Added to this, a completed study in cheese made with probiotic bacteria L. rhamnosus GG, L. rhamnosus LC 705, Propionibacterium freudenreichii ssp shermanii JS can reduce the prevalence of oral candidosis in the elderly and in addition, these microorganisms reduce hyosalivation and xerostomia [5]. Still, it evaluated the ability of commercial Lactobacillus plantarum 299v L., L. plantarum 931, L. rhamnosus GG ATCC 53103, L. rhamnosus LB21, L. paracasei F19, L. reuteri PTA 5289, L. reuteri ATCC 55730, L. acidophilus La5 in inhibiting the growth of Streptococcus mutans and Candida albicans for oral mucosa [7-9].

Also reducing the prevalence of oral Candida in complete denture wearers through the strains L. rhamnosus HS111 was evaluated, $L$. acidophilus HS101 [10-13]. Another important study examined the inhibitory effect of probiotic Streptococcus salivarius K12 on the in vitro growth of Candida albicans and therapeutic model animal oral candidiasis. This study showed that the probiotic inhibited adhesion of Candida albicans to the petri dish and also protected the animals from infection [14].

Thus, the major mechanisms of anti-Candida activity is due to probiotic nutritional competition, blocking the receptors for adhesins of Candida sp epithelial cells, adhesion to epithelial cells causing competition for adhesion site, increased intestinal peristalsis, increased rate of renewal of intestinal epithelial cells, changes in $\mathrm{pH}$, bacteriocin production (cationic, hydrophobic and heterogeneous with bactericidal and bacteriostatic effect) coagregation molecules, lactic acid, acetic acid, hydrogen peroxide and biosurfactants that resulted in the inhibition of growth of pathogen $[1,15]$. 


\section{Quantification of published articles (\%)}

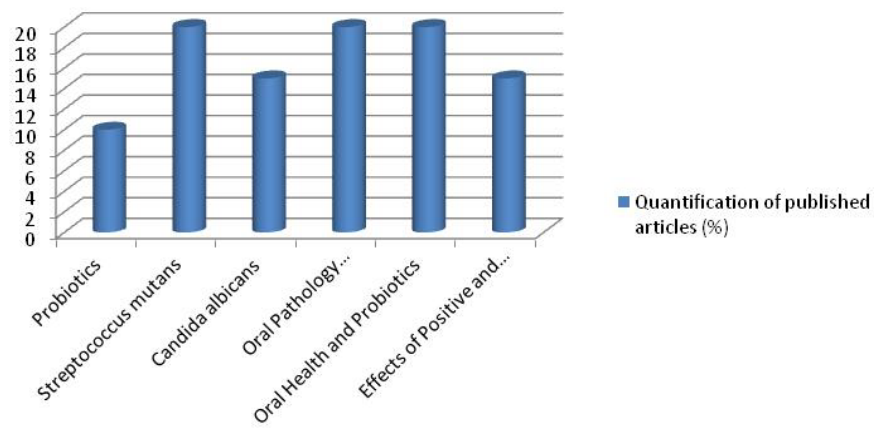

Figure 1. Graph showing the measurement in percentage of papers published between 1999 to 2015 on the themes Probiotics, Streptococcus mutans, Candida albicans, Microorganisms Oral Pathology, Oral Health and Probiotics and Positive and negative effects of probiotics.

In the oral cavity, the probiotic bacteria have the ability to modify the microbial balance of the host and reduce the growth of pathogens such as Candida [2,3]. For example, isolated strains L. paracasei subsp paracasei L. rhamnosus D6E saliva N8 and tested in vitro antimicrobial activity against $C$. albicans $[5,41]$.

Moreover, $\mathrm{m}$ preclinical study in mice showed that Lactobacillus acidophilus strain Lafti L10 reduced the number of Candida cells from the oral cavity by the action of interleukin 4 (IL \$) and IFN-y and nitric oxide (NO) in the saliva [1]. Lactobacilli have also the capacity to adhere to the mucosal epithelium, thereby competing for adhesion sites, and produce different metabolites such as hydrogen peroxide $\left(\mathrm{H}_{2} \mathrm{O}_{2}\right)$ and antifungics cyclic peptides which inhibit yeast growth.

\section{Discussion}

The efficient production of organic acids, which are a common feature of both Lactobacillus and Bifidobacterium may be detrimental to oral health $[1,2]$. We evaluated the cariogenicity of probiotic bacteria Lactobacillus salivarius in rats and they observed that inoculation of these microorganisms promoted an increase of cariogenic activity increasing the adhesion of S. mutans to tooth surface [2-4].

In addition, those same microorganisms have been related to oral health benefits, such as the production of inhibitory substances for growth of Streptococcus sobrinus, as well as reducing the risk of caries in children 3-4 years of age after the ingestion of milk containing Probiotic [3]. In addition, consumption of yogurt containing Lactobacillus reuteri decreased the oral Streptococcus mutans count [6]. Similar results were also obtained with strains of Lactobacillus reuteri and Bifidobacterium [7].

Other results demonstrated that there was no increase in the Streptococcus mutans count when administering a mixture of Lactobacillus probiotics in the form of capsules or liquid [8-12]. The survival of probiotic bacteria in the food product is of fundamental importance and must food contain at least one population of $10^{7} \mathrm{CFU} / \mathrm{g}$ of viable probiotic bacteria at the time of purchase of the product [6].

This concentration is recommended by some authors. However, it has been proposed that the minimum daily dose of probiotic culture is considered therapeutic and $10^{9}$ to $10^{8} \mathrm{CFU}$, which corresponds to a daily intake of $100 \mathrm{~g}$ of a product containing $10^{6}-10^{7} \mathrm{CFU} / \mathrm{g}$. It has been shown that the routine consumption and food processing may compromise the viability of the probiotic bacteria and interfere in the therapeutic benefit due to this consumption $[6,10]$.
For the probiotic is able to exert a anticariogenic effect, primarily the bacteria must be capable of adhering to the dental surface; second, it must become part of the biofilm; And finally, it must compete with cariogenic bacteria reducing the level of colonization of these $[1,2]$. Besides the bacterial genera, most fermented milk contains sugars and acid $\mathrm{pH}$ which can facilitate the adhesion of pathogens to the tooth surface and consequently the development of caries, so some vehicles such as milks, yoghurts, cheeses, chewing gums and tablets have been studied in an attempt to establish the most effective way of administering probiotics [2].

\section{Conclusion}

It was concluded that through pre-clinical and clinical action of probiotics on pathogenic microorganisms there is still enlightening results about the efficacy of probiotics, making it necessary to increase randomized multicenter studies, despite having potential to mitigate the incidence and prevalence oral diseases.

\section{Acknowledgement}

The work was supported by Ontological Clinic - São José do Rio Preto - SP, Brazil. We thank the Faculty Leopoldo Mandic of Campinas-SP, Brazil.

\section{Conflicts of interest}

The authors declare that they have no conflicts of interests.

\section{References}

1. Nozari A, Motamedifar M, Seifi N, Hatamizargaran Z, Ranjbar MA (2015) The Effect of Iranian Customary Used Probiotic Yogurt on the Children's Salivary Cariogenic Microflora. J Dent (Shiraz) 16: 81-86. [Crossref]

2. Nishihara T, Suzuki N, Yoneda M, Hirofuji T (2014) Effects of Lactobacillus salivariuscontaining tablets on caries risk factors: a randomized open-label clinical trial. $B M C$ Oral Health 14: 110. [Crossref]

3. Cortés-Dorantes N, Ruiz-Rodríguez MS, Karakowsky-Kleiman L, Garrocho-Range JA, Sánchez-Vargas LO, et al. (2015) Probiotics and their effect on oral bacteria count in children: a pilot study. Eur J Paediatr Dent 16: 56-60. [Crossref]

4. Ishizaka S, Matsuda A, Amagai Y, Oida K, Jang H, et al. (2014) Oral administration of fermented probiotics improves the condition of feces in adult horses. J Equine Sci 25 : 65-72. [Crossref]

5. Astekar M, Sidhu GK, Kathuria NS (2014) Impact of diet alteration on oral microflora by addition of probiotics. Indian J Med Microbiol 32: 466-467. [Crossref]

6. Ditu LM, Chifiriuc MC, Bezirtzoglou E, Marutescu L, Bleotu C, et al. (2014) Immunomodulatory effect of non-viable components of probiotic culture stimulated with heat-inactivated Escherichia coli and Bacillus cereus on holoxenic mice. Microb Ecol Health Dis 25. [Crossref]

7. Shetty SM, Shah DS, Goyal G, Kathuria NS, Abraham J, et al. (2014) A study to find the status of probiotics in New Delhi, India and review of strains of bacteria used as probiotics. J Int Soc Prev Community Dent 4: S18-22. [Crossref]

8. Nissen L, Sgorbati B, Biavati B, Belibasakis GN2 (2014) Lactobacillus salivarius and L. gasseri down-regulate Aggregatibacter actinomycetemcomitans exotoxins expression. Ann Microbiol 64: 611-617. [Crossref]

9. Shida K, Nomoto K1 (2013) Probiotics as efficient immunopotentiators: translational role in cancer prevention. Indian J Med Res 138: 808-814. [Crossref]

10. O’Bryan CA, Pak D, Crandall PG, Lee SO, Ricke SC (2013) The role of prebiotics and probiotics in human health. J Prob Health 1: 108.

11. Elavarasu S, Jayapalan P, Murugan T (2012) Bugs that debugs: Probiotics. J Pharm Bioallied Sci 4: S319-322. [Crossref]

12. Huang, G (2012) Regulation of phenotypic transitions in the fungal pathogen Candida albicans. Landes biocience C. Virulence 3:3, Beijing, China. [Crossref] 
13. Kaur MS, Pannu PK, Galhotra V (2012) Probiotics e A new way to maintain oral health. Ind J Dent 3: 77e 80.

14. Regis RR, Della Vecchia MP, Pizzolitto AC, Compagnoni MA, Souza PP, et al. (2012) Antimicrobial properties and cytotoxicity of an antimicrobial monomer for application in prosthodontics. $J$ Prosthodont 21: 283-290. [Crossref]

15. Narang S, Gupta R, Narang A (2011) Probiotics in oral healthcare review. Int J Sci Eng Res 2: 1-5.

16. Sohi RK, Bansal V, Veeresha KL (2011). Probiotics and oral health a review. SRM Univ J Dent Sci 2: 45-49.

17. Sheikh S, Pallagatti S, Kalucha A, Kaur H (2011) Probiotics. Going on the natural way. J Clin Exp Dent 3: 150-154.

18. Jindal G, Pandey RK, Agarwal J, Singh M (2011) A comparative evaluation of probiotics on salivary mutans streptococci counts in Indian children. Eur Arch Paediatr Dent 12: 211-215. [Crossref]

19. Nikawa H, Tomiyama Y, Hiramatsu M, Yushita K, Takamoto Y, et al. (2011) Bovine milk fermented with Lactobacillus rhamnosus L8020 decreases the oral carriage of mutans streptococci and the burden of periodontal pathogens. $J$ Investig Clin Dent 2: 187-196. [Crossref]

20. Grover HS, Luthra S (2011) Probiotics - The nano soldiers of oral health. J Indian Acad Clin Med 13: 48-54.

21. Darwazeh A (2011) Probiotics and oral disease: An update. Smile Dent J 6: 6-8.

22. Agarwal E, Bajaj P, Guruprasad CN, Naik S, Pradeep AR (2011) Probiotics: A nove step towards oral health. Arch Oral Sci Res 1: 108-115.

23. Manjunath RG (2011) Benefits of live microorganisms (Probiotics) in periodontal health. Int J Contemp Dent 2: 97-100.

24. Bhardwaj SB (2010) Probiotics and Oral health: An update. Int J Cont Dent 1: 116-119.

25. Bhushan J, Chachra S (2010) Probiotics their role in prevention of dental caries. J Oral Health Comm Dent 4: 78-82.

26. Barlow J (2010) The use of probiotics for oral health. The Clinical Use of Probiotics. Protexin Health Care 36-40.

27. Haukioja A1 (2010) Probiotics and oral health. Eur J Dent 4: 348-355. [Crossref]

28. Reddy JJ, Sampathkumar N, Aradhya S (2010) Probiótica em odontologia: revisão do estado atual da questão. Rev Clín Pesq Odontol Curitiba.
29. Staab B, Eick S, Knöfler G, Jentsch H (2009) The influence of a probiotic milk drink on the development of gingivitis: a pilot study. J Clin Periodontol 36: 850-856. [Crossref]

30. Cildir SK, Germec D, Sandalli N, Ozdemir FI, Arun T, et al. (2009) Reduction of salivary mutans streptococci in orthodontic patients during daily consumption of yoghurt containing probiotic bacteria. Eur J Orthod 31: 407-411. [Crossref]

31. Shimauchi H, Mayanagi G, Nakaya S, Minamibuchi M, Ito Y, et al. (2008) Improvement of periodontal condition by probiotics with Lactobacillus salivarius WB21: a randomized, double-blind, placebo-controlled study. J Clin Periodontol 35: 897-905. [Crossref]

32. Kõll P, Mändar R, Marcotte H, Leibur E, Mikelsaar M, et al. (2008) Characterization of oral lactobacilli as potential probiotics for oral health. Oral Microbiol Immunol 23: 139-147. [Crossref]

33. Machado AS (2008) Importância da microbiota intestinal para saúde humana enfocando nutrição, probioticos e dísbiose. (nome revista), Belo Horizonte.

34. Stamatova I, Kari K, Meurman JH (2007) In Vitro evaluation of antimicrobial activity of putative probiotic lactobacilli against oral pathogens. Int J Probiotics Prebiotics 2 225-232.

35. Caglar E, Kavaloglu SC, Kuscu OO, Sandalli N, Holgerson PL, et al. (2007) Effect of chewing gums containing xylitol or probiotic bacteria on salivary mutans streptococci and lactobacilli. Clin Oral Investig 11: 425-429. [Crossref]

36. Riccia DN, Bizzini F, Perilli MG, Polimeni A, Trinchieri V, et al. (2007) Antiinflammatory effects of Lactobacillus brevis (CD2) on periodontal disease. Oral Dis 13: 376-385. [Crossref]

37. Buriti FCA, Saad SMI (2007) Bacterias do grupo Lactobacillus casei: caracterização, viabilidade como probióticos em alimentos e sua importância para a saúde humana. Archivos Latinoamericanos de Nutrição 57, Caracas, Venezuela.

38. Yli-Knuuttila H, Snäll J, Kari K, Meurman JH (2006) Colonization of Lactobacillus rhamnosus GG in the oral cavity. Oral Microbiol Immunol 21: 129-131. [Crossref]

39. Kang MS, Chung J, Kim SM, Yang KH, Oh JS (2006) Effect of Weissella cibaria isolates on the formation of Streptococcus mutans biofilm. Caries Res 40: 418-425. [Crossref]

40. Bortowiski C, Leitis R, Pinto MB, Souza ER (2006) Aspectos microbiológicos da cárie dental. Aluscita, Bauru 25: 239-252.

41. Pustiglioni FE, Romito G A (1999) Influência das concavidades radiculares nas perdas clínicas de inserção, detectadas no exame clínico periodontal inicial. Rev Odontol Univ São Paulo 13: 375-381.

Copyright: (C2015 Gomes R. This is an open-access article distributed under the terms of the Creative Commons Attribution License, which permits unrestricted use, distribution, and reproduction in any medium, provided the original author and source are credited. 